\title{
Rancang Bangun Alat Pembengkok Kawat Metal Jig
}

\author{
Muhammad Yunus ${ }^{1)}$, Nanda Pranandita ${ }^{2)}$. \\ ${ }^{1,2}$ Jurusan Teknik Mesin, Politeknik Manufaktur Negeri Bangka Belitung \\ E-mail: ${ }^{1)}$ yunus@polman-babel.ac.id, ${ }^{2}$ nda.akano@gmail.com
}

\begin{abstract}
Abstrak
Sebuah UMKM (usaha mikro kecil menengah) di kota Pangkalpinang Provinsi Kep. Bangka Belitung dengan merk dagang "kebajig Lure" memproduksi metal jig atau umpan tiruan dari material logam. Salah satu permasalahan dalam proses pembuatan metal jig pada UMKM tersebut adalah pembengkokan kawat pada metal jig, karena proses pembengkokannya menggunakan tang loop yang menyebabkan kawat yang dibuat tidak seragam (dimana 10 kawat, dibawah 50\% kawat menyimpang dari toleransi) sehingga kawat yang menyimpang harus diperbaiki dulu sebelum proses pencetakan metal jig. Selain itu, waktu pembengkokan 1 buah kawat memerlukan waktu sekitar 80 detik. Penelitian ini bertujuan untuk mempercepat proses pembengkokan kawat metal jig dan didapatkan hasil kawat yang seragam dengan penyimpangan $\pm 0,2 \mathrm{~mm}$. Setelah dilakukan survey dan analisis awal maka pembuatan alat bantu dalam membengkokan kawat merupakan solusinya. Dalam proses pembuatan alat bantu tersebut menggunakan metode perancangan VDI 2222 yang dimulai dari merencana, mengkonsep, merancang, dan terakhir penyelesaian. Kemudian dilakukan proses pembuatan alat bantu dan uji coba pembengkokan kawat. Hasil dari uji coba yang dilakukan didapat tingkat keseragaman kawat metal jig sekitar $70 \%$ dan waktu yang diperlukan dalam proses pembengkokan 1 kawat adalah \pm 10 detik, dengan efisiensi \pm 70 detik dari proses sebelumnya. Dan dalam proses pencetakan metal jig, kawat yang diperbaiki sebelum proses pencetakan hanya sekitar $30 \%$.
\end{abstract}

Kata Kunci: metal jig, lure, pembengkokan kawat.

\section{Abstract}

An UMKM (micro, small and medium scale business) in the city of Pangkalpinang, Province of Kep. Bangka Belitung, with the trademark "kebajig Lure", produces metal jigs or artificial/fake bait made of metal. One of the problems in the process of making metal jigs at UMKM is bending the wire on the metal jig, because the bending process uses loop pliers which causes the wire to be made to be non-uniform (where 10 wires, below $50 \%$ of the wire deviates from tolerance) so that the stray wire must be repaired first before the metal jig molding process. In addition, the bending time of 1 piece of wire takes about 80 seconds. This study aims to accelerate the metal jig bending process and to obtain a uniform wire with a deviation of $\pm 0.2 \mathrm{~mm}$. After conducting the survey and initial analysis, the making of tools for bending wire is the solution. In the process of making these tools, the VDI 2222 design method is used, starting from planning, conceptualizing, designing, and finally finishing. Then carried out the process of making tools and testing wire bending. The results of the experiments conducted showed that the uniformity level of the metal jig wire was around $70 \%$ and the time required in the 1-wire bending process was \pm 10 seconds, with an efficiency of \pm 70 seconds from the previous process. And in the metal jig molding process, the wire repaired before the molding process is only about $30 \%$.

Keywords: metal jig, lure, wire bending.

Diterima 09 Juni 2021; direvisi terakhir 15 Juli 2021; diterbitkan 20 Juli 2021 


\section{PENDAHULUAN}

Metal Jig merupakan salah satu jenis umpan tiruan dalam memancing ikan (gambar 1a). Perbedaan metal jig dengan umpan tiruan yang lain adalah dari jenis material yang digunakan, metal jig menggunakan material logam. Material logam yang sering digunakan adalah timah, hal ini dikarenakan material tersebut mempunyai massa jenis yang tinggi dan dalam proses pengolahannya lebih mudah. Dalam memancing ikan dengan menggunakan umpan metal jig tidak memerlukan pemberat tambahan dan bentuk kontur dari umpan mengakibatkan gerak umpan seperti ikan [1]. Sehingga hal tersebut membuat para pemancing sangat menyukai metal jig dibandingkan umpan tiruan lainnya. Selain itu, ukuran mata dan warna umpan tiruan mempengaruhi ketertarikan ikan [2].

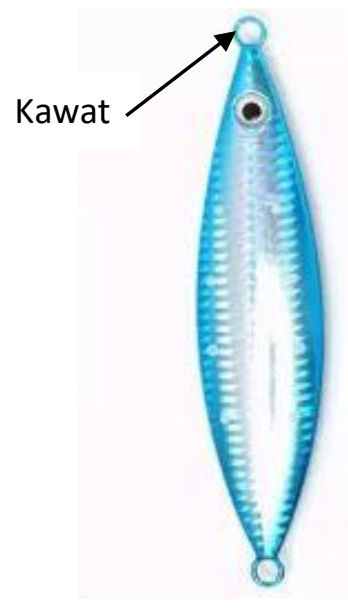

(a)

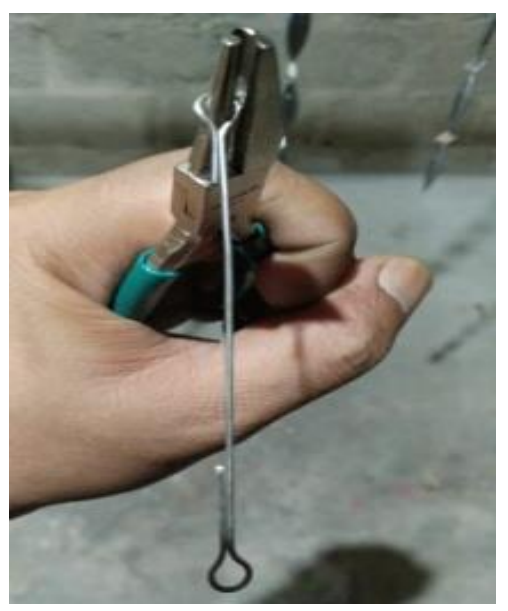

(b)

Gambar 1. (a) Metal Jig, (b) Proses pembengkokan kawat secara manual

Di Propinsi Kepulauan Bangka Belitung (Babel) tepatnya di Pangkalpinang ada UMKM yang memproduksi metal jig dengan merk dagang "Kebajig Lure” yang dikelola oleh Bapak Abang Setiady Wijaya. UMKM tersebut sudah memproduksi jenis/tipe metal jig diantarnya Ciu (berat 10gr,20gr, 30gr, 40 gr. 60gr, 80 gr,100gr, 120gr, 150gr, 200gr), Tamban (berat 10gr,20gr, 30gr, 40 gr. 60gr, 80 gr, 100gr, $120 \mathrm{gr}, 150 \mathrm{gr}$, 200gr), Teri (berat 10gr,20gr, 30gr, 40 gr. 60gr, 80 gr, 100gr, 120gr, 150gr, 200gr), dan Tudak (berat 10gr,20gr, 30gr, 40 gr. 60gr, 80 gr, 100gr, 120gr, $150 \mathrm{gr}, 200 \mathrm{gr})$. Produk “Kebajig Lure” tidak hanya dijual di pasar lokal dan nasional tetapi sudah menembus pasar internasional seperti malaysia, singapura, dll. Adapun jumlah permintaan pasar lebih dari 500 buah/minggu, dan permintaan teresbut 
selalu mengalami peningkatan. Peningkatan permintaan tersebut bukan tanpa alas an karena metal jig atau umpan tiruan semakin diminati karena produktivitas dalam memancing cukup baik. Bahkan para peneliti terus melakukan riset untuk meningkatakan produktifitas tangkapan salah satunya dengan pelapisan badan umpan dengan aluminium foil [3].

Masih sedikitnya penelitian terkait proses produksi dalam pembuatan metal jig skala UMKM menjadi alasan kuat dalam pengambilan tema ini. Dan diharapkan riset ini dapat membantu UMKM dalam meningkatkan produksi pembuatan metal jig. Karena UMKM merupakan salah satu sektor yang berkontribusi dalam peningkatan perekonomian Indonesia [4]. Salah satu permasalah UMKM dari pembuatan metal jig tersebut adalah pembengkokan kawat. Hal ini dikarenakan waktu yang diperlukan untuk membengkokan kawat sangat lama dan ukuran kawat yang dihasilkan tidak seragam. Selama ini UMKM masih menggunakan cara manual dalam pembengkokan kawat yaitu dengan menggunakan tang loop, tang cucut dan/atau tang snap ring seperti yang ditunjukan pada gambar 1b. Dari survey yang dilakukan, waktu yang diperlukan untuk membengkokan kawat dengan tang loop adalah \pm 80 detik per kawat. Sedangkan keseragaman hasil pembengkokan kawat (1/100 produk) hanya bisa tercapai kurang lebih $50 \%$.

Dalam penelitian ini hanya difokuskan pada pembuatan alat pembengkok kawat dengan satu varian produk metal jig saja yaitu varian Ciu ukuran 10gr, 20gr, 30, dan 40gr. Dimana ukuran diameter kawat $1 \mathrm{~mm}$, dan radius bendingnya 2,5 mm. Sedangkan panjang kawat setelah dibengkokan disesuaikan dengan berat dari metal jig.

\section{METODE PENELITIAN}

Metode penelitian yang digunakan pada riset ini terdiri dari 4 tahap, secara berturut-turut adalah pengumpulan data, merancang, membuat alat, dan uji coba (gambar 2). Dalam pengumpulan data langsung dilakukan survey ke UMKM yang memproduksi metal jig. Kemudian dalam perancangani menggunakan metode VDI 2222 (Verein Deutsche Ingenieuer / Persatuan Insinyur Jerman). Tahapan-tahapan dalam perancangan VDI 2222 adalah merencana/menganalisis, mengkonsep, merancang, dan penyelesaian [5]. Setelah proses perancangan selesai dilanjutkan proses pembuatan alat dan uji coba. Tahapan uji coba dilakukan untuk mengetahui 
fungsi alat dan pengambilan data untuk mengetahui bentuk kawat yang telah dibengkokkan dan waktu proses pembengkokkan.

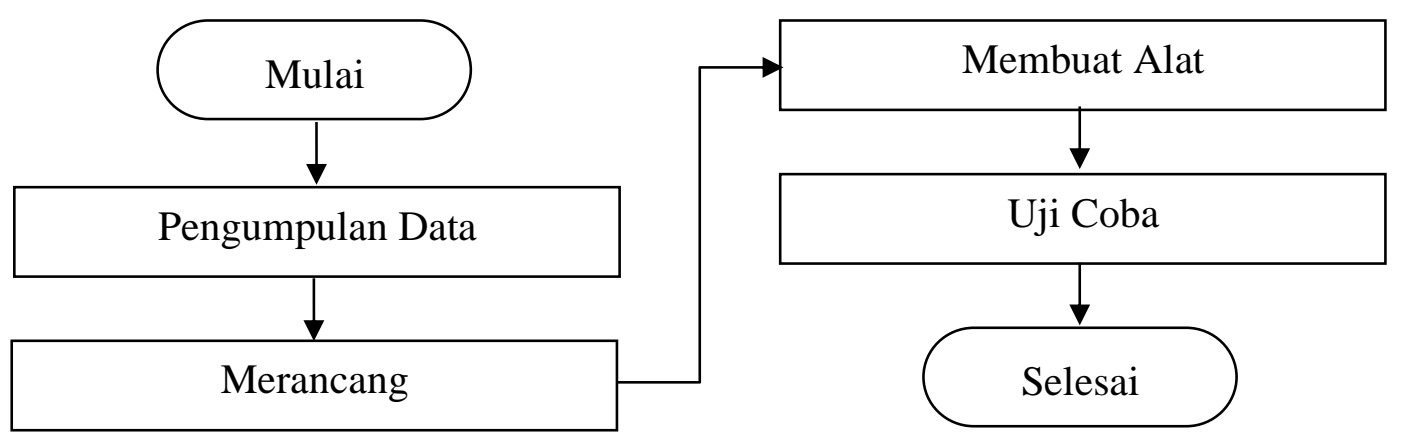

Gambar 2. Flowchart metode penelitian

\section{HASIL DAN PEMBAHASAN}

\section{a. Pengumpulan Data}

Pada tahapan ini, data yang dikumpulkan adalah proses pembuatan metal jig secara menyeluruh seperti yang ditunjukkan pada tabel 1. Pada tahapan proses tersebut, tahapan nomor 4 yang akan menjadi fokus pada penelitian ini.

Tabel 1. Tahapan proses pembuatan Metal Jig

\begin{tabular}{|c|l|l|l|}
\hline No. & $\begin{array}{c}\text { Tahapan } \\
\text { Proses }\end{array}$ & \multicolumn{1}{|c|}{ Deskripsi Proses } & \multicolumn{1}{|c|}{$\begin{array}{c}\text { Waktu / } \\
\text { Kapasitas }\end{array}$} \\
\hline 1 & $\begin{array}{l}\text { Desain } \\
\text { produk }\end{array}$ & $\begin{array}{l}\text { Desain mengacu pada jenis ikan yang } \\
\text { mudah dijumpai di Babel seperti ciu, } \\
\text { tamban, teri, \& tudak }\end{array}$ & $\begin{array}{l}\text { Satu kali proses } \\
\text { diawal }\end{array}$ \\
\hline 2 & $\begin{array}{l}\text { Pembuatan } \\
\text { master }\end{array}$ & $\begin{array}{l}\text { Master digunakan untuk membuat } \\
\text { cetakan }\end{array}$ & $\begin{array}{l}\text { Satu kali proses } \\
\text { diawal }\end{array}$ \\
\hline 3 & $\begin{array}{l}\text { Pembuatan } \\
\text { cetakan }\end{array}$ & $\begin{array}{l}\text { Cetakan dibuat dengan bahan dempul } \\
\text { (Polyester Putty) dengan acuan } \\
\text { master. Cetakan akan rusak jika } \\
\text { sudah digunakan beberapa puluh kali. } \\
\text { Kemudian akan menggunakan } \\
\text { cetakan baru. }\end{array}$ & $\begin{array}{l} \pm 2 \text { Cetakan/4 } \\
\text { jam } \\
\pm 50 \text { buah } \\
\text { produk/cetakan }\end{array}$ \\
\hline 4 & $\begin{array}{l}\text { Pembengko } \\
\text { kan Kawat }\end{array}$ & $\begin{array}{l}\text { Kawat dibengkokkan } \\
\text { dengan menggunakan } \\
\text { tang menjadi bentuk } \\
\text { seperti gambar } \\
\text { disamping. }\end{array}$ & $\begin{array}{l} \pm 45 \text { buah/jam } \\
\text { (menggunakan } \\
\text { tenaga yg sudah } \\
\text { terbiasa) }\end{array}$ \\
\hline
\end{tabular}




\begin{tabular}{|c|c|c|c|}
\hline 5 & $\begin{array}{l}\text { Proses } \\
\text { Cetak }\end{array}$ & $\begin{array}{l}\text { Kawat yang sudah dibengkokkan } \\
\text { dipasang dicetakan sesuai alurnya } \\
\text { kemudian cetakan ditutup dan } \\
\text { dicurahkan timah yang sudah cair. } \\
\text { Kemudian didinginkan sejenak } \\
\text { sampai beku setelah itu cetakan } \\
\text { dibuka dan produk dikeluarkan dari } \\
\text { cetakan. }\end{array}$ & $\begin{array}{l} \pm 50 \text { buah/jam } \\
\text { (jika } \\
\text { menggunakan } \\
\text { satu cetakan) }\end{array}$ \\
\hline 6 & $\begin{array}{l}\text { Finishing } \\
\text { permukaan } \\
\text { produk }\end{array}$ & $\begin{array}{l}\text { Hal ini dilakukan karena permukaan } \\
\text { produk hasil cetakan masih kasar. } \\
\text { Proses finishing dilakukan dengan } \\
\text { cara diamplas. }\end{array}$ & \pm 4 buah/jam \\
\hline 7 & Pengecatan & $\begin{array}{l}\text { Pengecatan dasar ini menggunakan } \\
\text { spray yang bertujuan agar lapisan } \\
\text { aluminium foil merekat dengan baik. }\end{array}$ & \pm 12 buah/jam \\
\hline 8 & Pelapisan & $\begin{array}{l}\text { Proses terakhir adalah pelapisan } \\
\text { produk dengan menggunakan } \\
\text { aluminium foil agar tampilan produk } \\
\text { menyerupai ikan. }\end{array}$ & \pm 12 buah/jam \\
\hline 9 & Produk jadi & $\begin{array}{l}\text { Total waktu yang diperlukan untuk } \\
\text { memproduksi } 100 \text { buah metal jig } \\
\text { selama } \pm 48 \text { jam }\end{array}$ & $\begin{array}{l}100 \text { buah metal } \\
\text { jig selama } \pm 48 \\
\text { jam ( } 6 \text { hari) }\end{array}$ \\
\hline
\end{tabular}

\section{b. Merancang}

Proses merancang dimulai dari tahapan merencana, mengkonsep, merancang, dan penyelesaian.

\section{1) Merencana}

Proses analisis dilakukan pemilihan pekerjaan dan penentuan kelayakan pekerjaan. Pemilihan dan penentuan kelayakan dilakukan konsultasi langsung dengan pengguna dan didapat permasalah seperti yang dtampilkan pada tabel 2 berikut. Dan fokus pada penelitian ini adalah hasil pembengkokan kawat tidak seragam dan memerlukan waktu cukup lama karena prosesnya manual dengan menggunakan tang. Agar didapat ukuran kawat yang seragam maka tetap menggunakan kaidah-kaidah ilmu proses pembengkokan kawat [6].

\section{2) Mengkonsep}

Mengkonsep secara berturut-turut terdiri dari membuat daftar tuntutan, penguraian fungsi keseluruhan, alternatif fungsi bagian, varian konsep, penilaian varian konsep, keputusan. Daftar tuntutan dapat dilihat pada tabel 3, sedangkan 
penguraian fungsi keseluruhan hinnga penilaian varian konsep dilewatkan pada tulisan ini. Dalam pembuatan konsep hingga selesai mengacu pada pergerakanpergerakan mekanik [7].

Tabel 2. Permasalahan mitra

\begin{tabular}{|c|c|}
\hline Aspek & Permasalahan prioritas \\
\hline \multirow[t]{4}{*}{$\begin{array}{l}\text { Produksi \& } \\
\text { manajemen }\end{array}$} & $\begin{array}{l}\text { - Waktu proses finishing sangat lama ( } 1 \text { produk waktu yang } \\
\text { diperlukan } \pm 15 \text { menit) hal ini dikarenakan permukaan produk } \\
\text { setelah dicetak kurang halus. }\end{array}$ \\
\hline & $\begin{array}{l}\text { - } 1 \text { cetakan hanya } 1 \text { cavity (karena proses pembuatan cetakan } \\
\text { hanya menggunakan } 1 \text { master), hal ini menyebabkan waktu } \\
\text { proses cetak lebih lama. }\end{array}$ \\
\hline & $\begin{array}{l}\text { - Pembuatan cetakan berulang-ulang (1 cetakan untuk } \pm 50 \\
\text { produk) karena cetakan terbuat dari dempul (Polyester Putty) }\end{array}$ \\
\hline & $\begin{array}{l}\text { - Hasil pembengkokan kawat tidak seragam dan memerlukan } \\
\text { waktu cukup lama karena prosesnya manual dengan } \\
\text { menggunakan tang. }\end{array}$ \\
\hline
\end{tabular}

Tabel 3. Daftar tuntutan

\begin{tabular}{ccl}
\hline No & Tuntutan Utama & \multicolumn{1}{c}{ Deskripsi } \\
\hline 1 & Dimensi akhir kawat & - Untuk dimensi lubang $3 \mathrm{~mm}$ dan $3,5 \mathrm{~mm}$ \\
& seragam & - Untuk panjang akhir kawat adalah $73 \mathrm{~mm}$ \\
& Waktu & Proses pembengkokkan < 30 detik \\
\hline 2 & Lebih dari 1 ukuran & Alat dapat digunakan untuk beberapa ukuran \\
\hline 3 & panjang kawat & Panjang kawat \\
\hline 4 & Pengoperasian & Mudah dioperasikan tanpa keahlian khusus \\
\hline No & Tuntutan Tambahan & Deskripsi \\
\hline 1 & Perawatan & Tidak memerlukan perawatan khusus \\
\hline 2 & Biaya & Biaya max. 2 juta \\
\hline 3 & Perakitan & Untuk pemasangan dan pembongkaran alat \\
& Konstruksi alat & Sederhana dan mudah dipindahkan \\
\hline 4 & &
\end{tabular}




\section{3) Merancang}

Dalam proses merancang didapat rancangan seperti yang diperlihatkan pada gambar 3. Terdapat fungsi body, pengatur Panjang kawat, pengatur diameter bengkok, dan fungsi poros pembengkok. Adapun tahapan merancang adalah membuat gambar draft, melakukan optimasi, dan finalisasi gambar draft. Pada tahapan optimasi dilakukan modifikasi pada poros pembengkok agar proses pembengkokan hanya satu kali untuk setiap lubang.

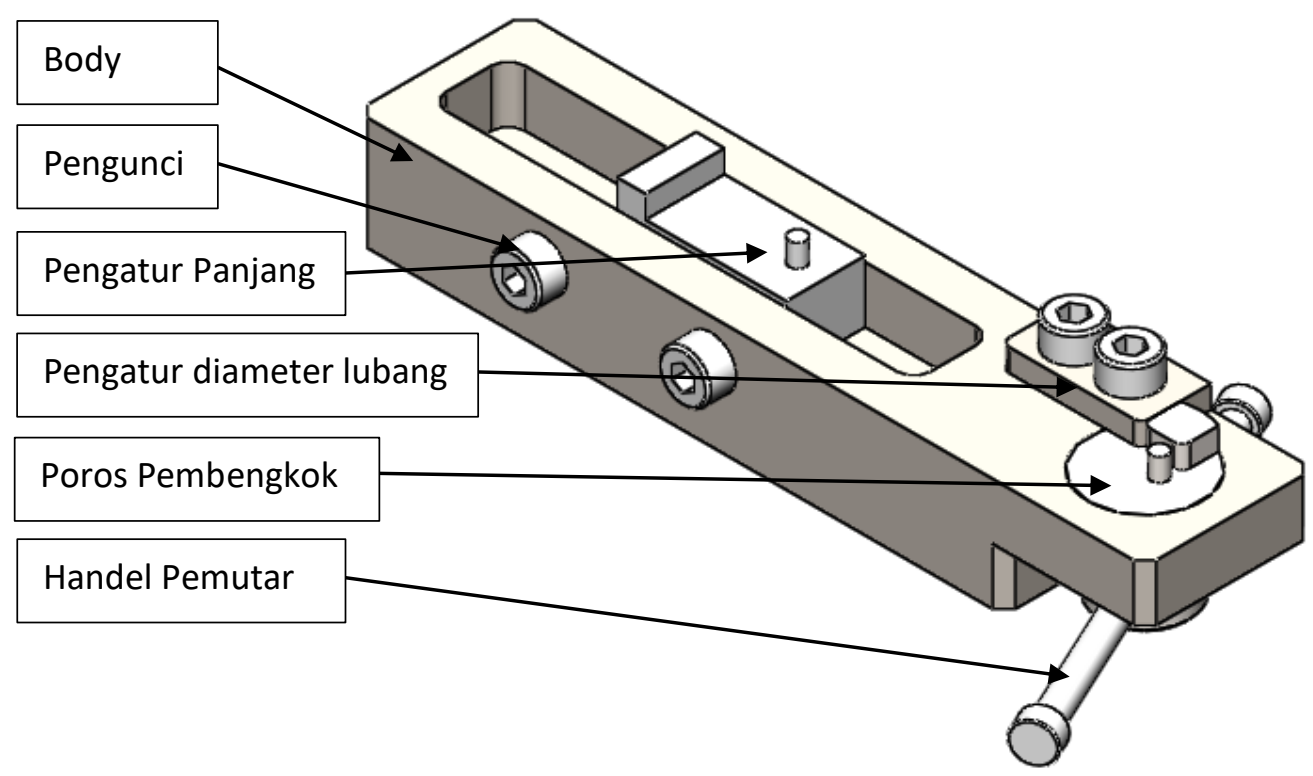

Gambar 3. Keputusan varian konsep

\section{4) Penyelesaian}

Pada tahap penyelesaian dilakukan pembuatan gambar kerja yaitu gambar susunan dan gambar bagian. Adapun jumlah bagian atau komponen desain alat pembengkok kawat metal jig adalah 14 bagian yang terdiri dari 7 komponen yang diproses pemesinan dan 7 komponen standard yang berupa baut inbus.

\section{c. Membuat Alat}

Pembuatan alat dilakukan di bengkel Polman Negeri Babel, dalam proses pemesinan yang banyak digunakan adalah proses frais/milling dan proses turning/bubut. Adapaun hasil dari alat yang dibuat dapat dilihat pada gambar 4 berikut. 


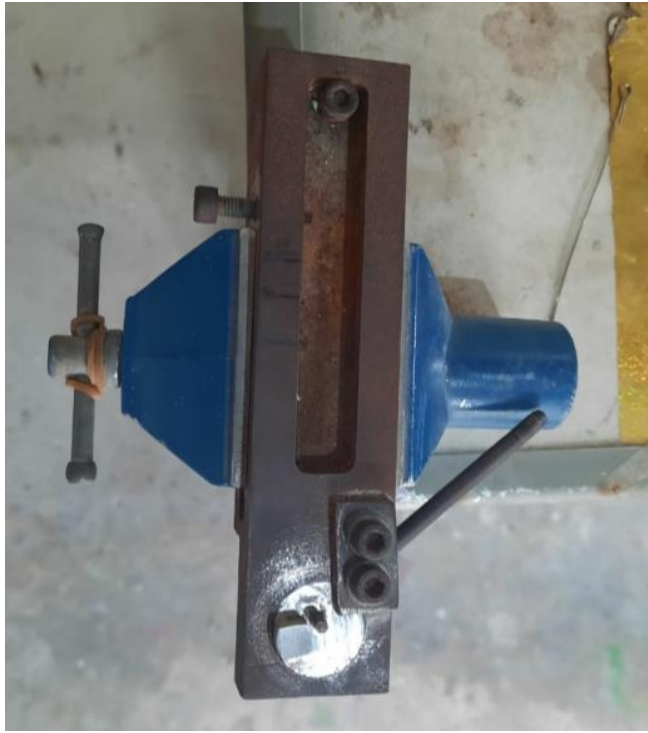

a

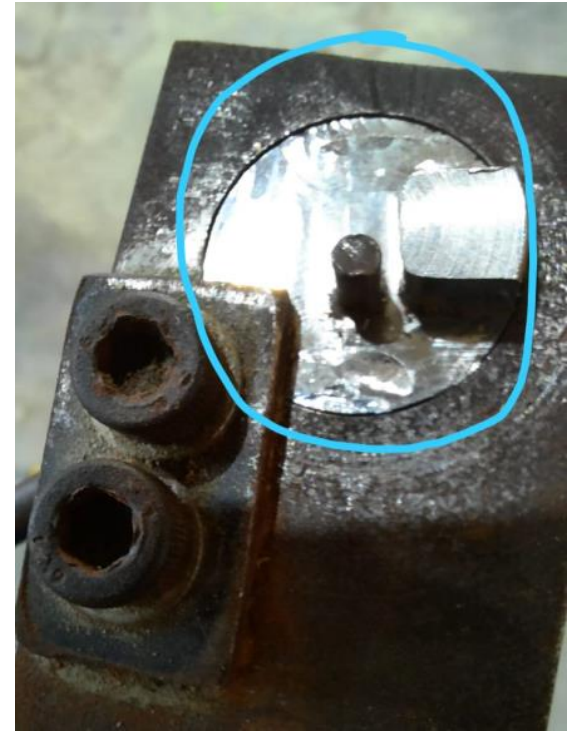

$\mathrm{b}$

Gambar 4. a) alat bengkok kawat metal jig, b) poros pembengkok

\section{d. Uji coba}

Pengambilan data pada tahap uji coba mengacu pada daftar tuntutan yang telah dibuat yaitu dimensi akhir kawat dan waktu proses pembengkokan kawat. Adapun hasil uji coba dapat dilihat pada tabel 4. Pengaturan panjang varian kawat yang digunakan dalam pengujian ini adalah $73 \mathrm{~mm}$. Dari hasil uji coba ada 3 kawat yang menyimpang dari toleransi yaitu kawat 2, 4, dan 7. Sedangkan waktu proses pembengkokan sudah dihitung pada kedua sisi kawat dengan rata-rata 9,9 detik.

Tabel 4. Hasil uji coba

\begin{tabular}{|c|c|c|c|c|}
\hline \multirow{2}{*}{ No. } & \multirow{2}{*}{ Nama Kawat } & \multicolumn{2}{|c|}{ Ukuran kawat $(\mathrm{mm})$} & \multirow{2}{*}{ Waktu (detik) } \\
\cline { 3 - 4 } & & Dia. lubang & Panjang & 11 \\
\hline 1 & Kawat 1 & 3,25 & 73,20 & 12 \\
\hline 2 & Kawat 2 & 3,35 & 73,25 & 11 \\
\hline 3 & Kawat 3 & 3,25 & 73,15 & 10 \\
\hline 4 & Kawat 4 & 3,35 & 73,30 & 9 \\
\hline 5 & Kawat 5 & 3,30 & 73,10 & 9 \\
\hline 6 & Kawat 6 & 3,30 & 73,15 & 8 \\
\hline 7 & Kawat 7 & 3,35 & 73,25 & 10 \\
\hline 8 & Kawat 8 & 3,25 & 73,05 & 9 \\
\hline 9 & Kawat 9 & 3,20 & 73,00 & 10 \\
\hline 10 & Kawat 10 & 3,35 & 73,05 & 9,90 \\
\hline
\end{tabular}




\section{KESIMPULAN}

Alat pembengkok kawat yang dibuat dapat mengurangi waktu produksi pembengkokan kawat pada UMKM “Kebajig Lure” hingga 70 detik per-kawat, hal ini dapat dilihat dari hasil uji coba yang dilakukan pada 10 buah kawat, dimana waktu pembengkokan rata-rata adalah 9,9 detik sedangkan waktu pembengkokan secara manual dengan menggunakan tang adalah 80 detik. Dan keseragaman hasil uji coba hingga $70 \%$ dengan toleransi \pm 0.2 , sisa $30 \%$ yang menyimpang dari toleransi dikarenakan kelonggaran dari poros pembengkok terhadap body alat, tapi hal ini dapat disiasati dengan cara mengatur pengatur panjang pada alat. Desain alat ini juga dapat digunakan untuk lebih dari satu varian panjang kawat karena adanya fungsi pengatur panjang kawat. Selain itu, daftar tntutan lain seperti pengoperasian, perawatan, biaya pembuatan, perakitan dan konstruksi alat dapat terpenuhi.

\section{DAFTAR PUSTAKA}

[1] A. La Ode, A. Luasunaung, and W. Patty, "Studi tentang bentuk umpan buatan terhadap hasil tangkapan ikan selar (Caranx melamphygus) dengan pancing noru di sekitar rumpon,” Jurnal Ilmu Dan Teknologi Perikanan Tangkap, vol. 1, Nov. 2014.

[2] F. I. Maspeke, G. Puspito, and I. Solihin, “Kombinasi Ukuran Mata Pancing Dan Warna Umpan Tiruan Untuk Meningkatkan Hasil Tangkapan Huhate," Jurnal Penelitian Perikanan Indonesia, vol. 24, no. 4, p. 239, Mar. 2019.

[3] R. Caesario, R. Yusfiandayani, and D. Diniah, "Produktivitas Umpan Tiruan Dari Kayu Berlapis Alumunium Foil Pada Pancing Ulur,” Jurnal Teknologi Perikanan dan Kelautan, vol. 7, no. 2, pp. 125-136, Feb. 2017.

[4] R. Rita Purwaningsih dan N.Asandimitra Haryono, "Sumber Daya Manusia, Operasional, Pemasaran, Dan Kebijakan Pemerintah Terhadap Kinerja UMKM Di Kota Surabaya,’Jurnal Ekonomi dan Bisnis, Vol.12, No.2, pp. 390-409, 2019.

[5] A. I. Komara, and Saepudin, "Aplikasi Metoda VDI 2222 Pada Proses Perancangan Welding Fixture Untuk Sambungan Cerobong Dengan Teknologi 
CAD/CAE," Jurnal Ilmiah Teknik Mesin Cylinder, vol. 1 No. 2, pp. 1-8, Oct. 2014.

[6] R. N. Wright, “Wire Forming,” Wire Technology, pp. 273-284, 2016.

[7] Hiscox, G. D., 1800 Mechanical Movements, Device and Appliances, Dover Publications, inc., New York, 2007. 